\title{
Influences of ethnicity on perinatal and child mortality in the Netherlands
}

\author{
T W J Schulpen, J E van Steenbergen, H F van Driel
}

\begin{abstract}
Aims-To investigate the differences in perinatal death and child mortality between different ethnic groups in the Netherlands.

Methods-Retrospective analysis of data collected between 1990 and 1993 in the national obstetric registry comprising 569743 births. Retrospective analysis of all death certificates of 0 to 15 year old children routinely collected between 1979 and 1993, comprising 20211 deaths.

Results-Black mothers had the highest perinatal death rate compared with indigenous Dutch mothers (odds ratio 2.2). Hindustanis (West Indian Asians) had an odds ratio of 1.4 and Mediterraneans 1.3. The increased rate for black and Hindustani women could be fully explained by preterm birth. In the Mediterranean group the differences were explained by teenage pregnancy, grand multiparity, and socioeconomic status rather than prematurity. The death rate of Turkish and Moroccan children was twice as high as that of native Dutch children. For the different diagnostic categories this was: infectious diseases, relative risk (RR) 2.2; hereditary (metabolic) disorders, RR 2.0; accidents and drowning, $R R$ 1.9. One quarter of the Turkish and Moroccan children died while on holiday in their country of origin. Sudden infant death syndrome was twice as high for Turkish infants as for Dutch children and four times higher than for Moroccan infants. Conclusion-Ethnic minorities in the Netherlands have a higher perinatal and child mortality rate than the indigenous Dutch. Apart from socioeconomic differences, sociocultural and lifestyle factors play an important role.

(Arch Dis Child 2001;84:222-226)
\end{abstract}

Keywords: death; mortality; sudden infant death syndrome; ethnic group; Netherlands; social environment

Wilhelmina Children's Hospital, Huispost KE 04-153.0, Postbus 85090, 3508 AB Utrecht, Netherlands T W J Schulpen $\mathrm{J}$ E van Steenbergen $\mathrm{H} F$ van Driel

Correspondence to: Prof. Schulpen t.schulpen@wkz.azu.n

Accepted 19 October 2000
The Netherlands has nearly 16 million inhabitants of whom 1.3 million are from ethnic minorities, amounting to nearly $9 \%$ of the
Differences in perinatal and childhood morhave been reported in several countries including Germany, Belgium, and Sweden. ${ }^{1-3}$ They are often ascribed to socioeconomic factors or instances, however, there is no clear cut explanation. population. The largest group came as migrant labour in the 1960s from Islamic Mediterranean countries, chiefly Turkey and Morocco. Between 1986 and 1990 the number of Turkish people in the Netherlands increased by $22 \%$ to over 200000 persons while the Moroccans grew by $27 \%$ to 170000 . This was a result of family reunification in the 1980 s and to a birth rate twice as high as that of the indigenous Dutch population. ${ }^{4}$ In 1975 the former Dutch colony of Surinam in South America became independent and 200000 persons (blacks and Hindustani) came to the Netherlands, soon followed by around 80000 Carribeans from the Netherlands Antilles. Nearly half of the migrant population live in the four major cities, where $15 \%$ of the population and $40-50 \%$ of the children are of foreign descent (that is, people born abroad with at least one parent born abroad, and people born in the Netherlands with both parents born abroad in a nonindustrialised country not belonging to the rich OECD group). ${ }^{5}$

Apart from migrant labourers and excolonial movements, an increasing number of refugees and asylum seekers are entering the Netherlands. Since 1993, approximately 40000 persons seek asylum each year, many of whom will stay as accepted immigrants. One quarter of them are children under 16 years of age. ${ }^{6}$

From two previous studies we know that ethnicity influenced perinatal and child mortality in the Netherlands, ${ }^{78}$ but studies were small and limited in time. The introduction of a nationwide obstretic registry scheme and the use of data of the Central Bureau of Statistics created the possibility to conduct a nationwide study. ${ }^{9}$

\section{Perinatal death}

METHODS

In the Netherlands about 197000 children are born each year. Around 85\% are registered in the Dutch National Obstetric Registry (LVR, Landelijke Verloskundige Registratie). The LVR is a (voluntary) registry to which participating midwives and obstetricians send data on women and newborns delivered both at home and in hospital. The last care provider completes the forms and sends the data to LVR-1 (for midwives) or LVR-2 (for obstetricians). An analysis was done by van Enk et al based on all singleton pregnancies registered from 1990 to $1993 .{ }^{10}$ Data from 569743 of the total of 777564 singleton pregnancies were analysed; $15 \%$ of these pregnancies occurred in non-Dutch women ( $n=85$ 527). In the LVR the ethnicity of the women is registered on the 
basis of ethnic and geographical background. Ethnicity is divided into seven categories: Dutch, Mediterranean, Black, Hindustani, Asian, Non-Dutch European, and "others".

Dutch women are defined as born in the Netherlands and of West European origin. Mediterraneans consist of Turkish and NorthAfrican (mainly Moroccan) women. Most of the black women have their origins in Surinam and the Dutch Antilles. The Hindustani are West Indian Asian women from Surinam and the Dutch Antilles. The Asian women are mainly Chinese, Malaysian, and Moluccan (Indonesian). Non-Dutch European women are from Western and Eastern Europe. The group "others" comprises women of mixed, unknown, or other ethnicity. It mainly consists of refugees and asylum seekers. The ethnicity of the women is classified by the care provider.

Perinatal death in the LVR is defined as death occurring after the sixteenth week of gestation to seven days after birth. As the registration forms are usually completed soon after discharge of the mother from hospital, perinatal death after the first 24 hours is poorly registered, so not included in this study.

As socioeconomic status may influence the risk of perinatal death, we included this in the analysis. We assessed socioeconomic status for 42282 women who gave birth in the three major cities of Amsterdam, Rotterdam, and Utrecht. Women were divided into four categories of socioeconomic status (SES) based on postcode. The postcode number can be used as a proxy measure for income and rate of unemployment. Each postal area comprises around 10000 persons.

We present only results of this research project, as an extensive account of the methods and analysis has been published elsewhere. ${ }^{11}$

RESULTS

Perinatal death occurred most frequently among black women $(3.4 \%)$. Their chance of perinatal death was twice as high as that in Dutch women (1.4\%; relative risk (RR): 2.2 ; 95\% confidence interval (CI): 1.2 to 2.4 ). For Hindustanis the relative risk was significant but less pronounced (RR: 1.3 ; 95\% CI: 1.2 to 1.6 ). By logistic regression analysis we could explain the differences for both groups completely by a higher frequency of immature and premature delivery. Socioeconomic status, parity and age had no influence in these groups. In the Mediterranean group the chance of perinatal death was also significantly higher compared to the Dutch group (RR: 1.3 ; 95\% CI: 1.2 to 1.4 ). Prematurity was not the explanation; it was a result of teenage pregnancies and grand multiparity. Socioeconomic status, as defined in this study, had minimal influence.

Immigrants from other European countries and from the Far East had the same perinatal death rate as the Dutch population. The group "others" had a relative risk of 1.8 (95\% CI: 1.5 to 2.0 ), for which prematurity was only partly an explanation.

\section{Mortality of $0-15$ year old children} METHODS

In a retrospective analysis of routinely collected vital statistics (census and mortality), we analysed all death certificates from the Central Bureau of Statistics (CBS) of 0-15 year old children who died between 1979 and 1993 (20 211 cases) according to ICD-9 codes. Causes of death are verified by the attending physician who always has to complete the CBS registration form. In cases where death has taken place abroad we classified registration as "incomplete" as no registration form was available. Stillbirth and early neonatal death (0-7 days) were excluded, because registration in this age group was not optimal. We divided data into three five-year periods and three age groups: $0,1-4,5-15$ years, following the infant, preschool, and school life period. As ethnicity and nationality correspond in the studied timeframe for Turkish and Moroccan children residing in the Netherlands, we used nationality to approximate ethnicity. For children from Surinam and the Netherlands Antilles this was not possible, as they all have Dutch nationality. We compared data of Turkish and Moroccan children with those of children with Dutch nationality. Of the 20211 death certificates, 1764 were of children with Turkish or Moroccan nationality.

\section{RESULTS}

The overall relative mortality risk for both Turkish and Moroccan children diminished from 3.2 (90\% CI: 3.12 to 3.25) in the first five year period to 2.2 (90\% CI: 2.17 to 2.32$)$ in the second. After 1988 however we observed no further decline and the relative mortality risk remains 2.1 (90\% CI: 2.00 to 2.15$)$.

Figure 1 presents causes of death for Turkish, Moroccan, and Dutch infants in the period 1979-1993. In the age group under 1 year (week 1-52) there is a significant difference in infectious diseases, congenital hereditary (especially metabolic) disorders, and sudden infant death syndrome (SIDS). In the latter group the rate for Turkish infants is twice as high as for Dutch infants and four times as high as for Moroccan infants. In the 1-4 year old group (data not shown) hereditary disorders and external causes such as accidents and drowning cause most mortality differences between the three groups. In the 5-14 year old children (data not shown) the differences can mainly be attributed to external causes. More than a quarter of deaths among Turkish and Moroccan children occurred while travelling to or staying in their country of origin. We assessed the causes of these deaths as "incomplete/unknown".

\section{Hereditary disorders}

The relative risk for Turkish and Moroccan children to die from a hereditary disorder is 2.0 (95\% CI: 1.8 to 2.2 ). Further analysis shows that metabolic disorders and other autosomal recessive diseases are the main causes of death. 


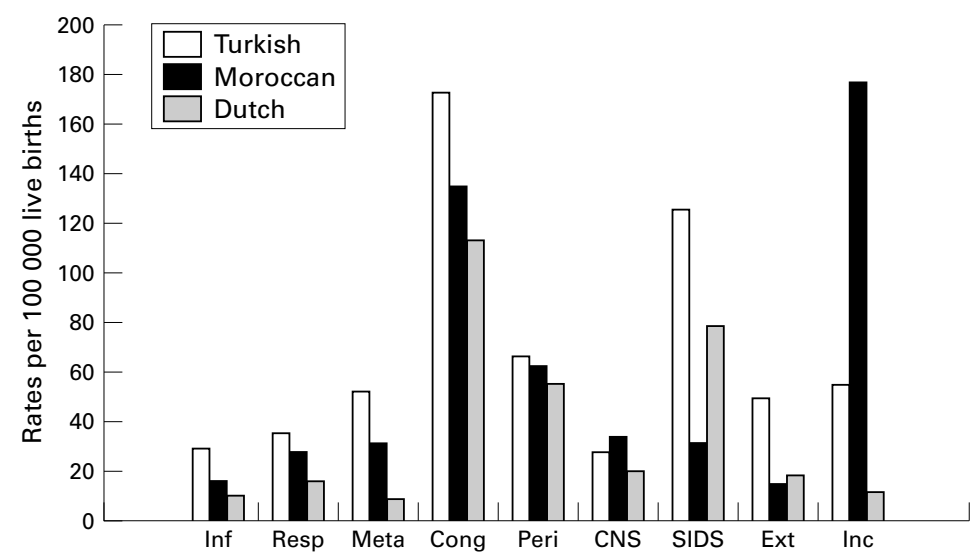

Figure 1 Causes of death in 1 week to 1 year old children (1979-1993). Inf, infectious diseases; Resp, respiratory diseases; Meta, metabolic disorders; Cong; congenital disorders; Peri, perinatal problems; CNS, CNS disorders; SIDS, sudden infant death syndrome; Ext, external causes; Inc, incomplete data.

Infectious diseases

The relative risk for Turkish and Moroccan children dying from infectious diseases is 2.2 (95\% CI: 1.8 to 2.9 ). While the absolute number of children dying from infectious diseases is relatively small, the differences are significant. Within these diseases, meningitis and acute respiratory infections are more frequent causes of death for Turkish and Moroccan children.

External causes of death

External causes of death have a relative risk of 1.9 (95\% CI: 1.6 to 2.2 ). They are mainly accidents and drowning.

Sudden infant death syndrome

Turkish children have a risk ( 1.65 per 1000 live born infants) of dying from SIDS that is four times that of Moroccan children (0.4 per 1000 live born infants). For Dutch children the overall incidence in this 15 year period was 0.80 per 1000 live born infants. The relation between the different relative risks of SIDS remained constant over time, but the actual number of SIDS cases declined dramatically over the past five year period for all three groups.

\section{Incomplete}

This group comprises those who died outside the Netherlands because no death certificate was sent to the Central Bureau of Statistics.

Although diminishing over time, death abroad remains the major category among the causes of death: $31 \%, 26 \%$, and $22 \%$ respectively of all deaths in the three five year periods. As cause of death was not verified by an attending physician we used another model. Between 1982 and 1993 the main causes death of Turkish and Moroccan children living in Amsterdam who died while abroad were collected by verbal autopsy. The top three causes were accidents (35\%), infections (21\%, diarrhoea and dehydration in particular), and congenital disorders $(11 \%)$. $^{12}$

\section{Discussion}

The perinatal mortality rates as measured by the LVR are based on $85 \%$ of all singleton pregnancies during the period 1990-1993. This is partly a result of voluntary registration, in which general practitioners do not participate (around $12 \%$ of all deliveries in the Netherlands), and partly to the exclusion of all deaths after 24 hours. The influence of this exclusion is equally divided over the different ethnic groups, as has been found in a study in Utrecht. In this study by van Driel et al, a more detailed analysis on perinatal death, utilising a more refined SES classification at neighbourhood level with around 3000 inhabitants per area was performed among all 28211 children (97\% singleton) born between 1983 and 1992 based on the municipal birth registry of Utrecht, the fourth largest city of the Netherlands. ${ }^{13}$ Here the odds ratio for the black population was the highest (OR: 2.0; 95\% CI: 1.3 to 3.2), followed by the Moroccans (OR: 1.9; 95\% CI: 1.5 to 2.6 ) and the Turks (OR: 1.6 ; 95\% CI: 1.1 to 2.3 ). A multivariate analysis showed that ethnicity was an independent risk factor if controlled for SES.

It has been reported in the USA that perinatal mortality and preterm birth in Blacks is twice as high as in Whites, Chinese, and South East Asians and also higher than in immigrants from the Indian subcontinent and South or Central America. ${ }^{14}{ }^{15}$ In some studies in the USA, it has been shown that differences persisted after correction for socioeconomic status. ${ }^{16}$

Recently, studies have found that the difference in preterm birth rate between Whites and Blacks is related to a higher rate of bacterial vaginosis and genital infections. ${ }^{17-19}$ The reasons are not clear and can only be ascribed partially to sexual behaviour. ${ }^{20}$ Vaginal douching, especially with "Dettol", a common health care practice of black women in the USA and in the UK, ${ }^{21}{ }^{22}$ has been suggested as one cause.

The higher perinatal death rate associated with a high preterm birth rate is also found in the groups of Hindustanis and "others", though less pronounced. As the countries of origin of some among these groups were also those of the black community, we hypothesise that they share risk factors related to common lifestyle, behavioural patterns, or health care habits.

Other possible explanations could be the life circumstances of the black Surinam mothers, of whom $50 \%$ are unmarried. There are no data on possible genetic differences.

Considering children aged $0-14$ years, the number of deaths to be expected among Turkish and Moroccan children living in the Netherlands should be 714 instead of the recorded 1764. Although we excluded early neonatal death, this was so for both Dutch and foreign children. We are currently analysing reasons for early neonatal death in the four major cities.

In the period under study $90 \%$ of the studied ethnic groups hold their original nationality. ${ }^{23}$ Therefore nationality was used as a proxy for ethnicity. After 1993 new legislation made it possible to combine two nationalities. The ratios for ethnic Turkish and Moroccan people might be slightly lower than the presented ratios for the Turkish and Moroccan nationals. 
Death abroad is the major cause of death for children aged $0-15$ years. "Health and holiday" educational campaigns in under- 5 and school clinics were started in the mid-1980s by national and local government. ${ }^{9}$ The decline in mortality risk between the first and the second five year period under study (from 3.2 to 2.2 ) can be partly attributed to the decline in death abroad.

Regarding SIDS, differences in child care practices and other lifestyle factors between the different ethnic groups need to be studied further. A special working party currently undertakes (verbal) autopsy within 24 hours after death. The national anti-SIDS campaign of 1989 has influenced all three groups equally. The overall cot death incidence decreased from 1.2 per 1000 live born infants in 1987 and 1988 to 0.35 in $1993 .^{24}$ At present the incidence has further fallen to 0.14 per 1000 live born infants.

We cannot explain the striking differences in SIDS between Turkish and Moroccan children. We do not believe this is a registration artefact as the deaths abroad, registered as incomplete, occur in both communities. Differences in sleeping position have not been found; we are currently investigating differences in child care practices. The only important difference which has been confirmed is smoking. The percentage of smokers in the Turkish, Dutch, and Moroccan community for men and women is respectively: 56 and $21 \%, 47$ and $38 \%$, and 34 and $1.5 \% .^{25} 26$

In the study period between 1979 and 1993 the autopsy rate among children suspected of SIDS was about $60 \%$. Autopsy rates were equally low in Turkish and Moroccan children because of religious reasons, so cannot be an explanation for the fourfold difference found.

Consanguinity is the most probable explanation for increased rates of hereditable disorders. This was also found in the UK for Pakistani and other ethnic minorities. ${ }^{27} 28$ In Turkey and Morocco around 30\% of the marriages are consanguineous. ${ }^{29}{ }^{30}$ It is known that metabolic disorders such as phenylketonuria (PKU) have an incidence in Turkey of 1 in $4000^{31}$ compared to 1 in 16000 in the Netherlands. At present around $50 \%$ of marriages in the Turkish and Moroccan community in the Netherlands are with a partner who has come directly from the home country. We estimate that around half of these partners are nieces or nephews. Public awareness of the risks of niece-nephew marriages might reduce the incidence of these disorders.

External causes of death are mainly accidents and drowning. The number of traffic accidents may be related to low socioeconomic status and poor housing facilities. This is in accordance with morbidity data, showing that the Turkish and Moroccan children are more often involved in traffic accidents. ${ }^{32}$ This is less likely for drowning. Research in Amsterdam showed that only $56 \%$ of the $13-14$ year old Turkish and Moroccan girls have a swimming certificate, ${ }^{33}$ whereas over $95 \%$ of the native Dutch children of this age have this certificate. Most schools are economising on school swim- ming, which normally starts for the $7-8$ age group. Native Dutch parents often pay for swimming lessons which may account for the difference in swimming skills between children of different ethnic backgrounds.

The comparative high rate of death caused by infectious diseases might be a result of late recognition of serious signs and symptoms by the children's care takers. This was confirmed by Schilder, ${ }^{34}$ who performed a qualitative analysis of 72 Turkish and Moroccan children who died between 1992 and 1995 in the city of Rotterdam. Apart from lack of knowledge, social isolation and lack of authority of the mother resulted in delays in consulting doctors. Poor knowledge of the Dutch language and different cultural values were also risk factors. It is known that the existing health education programmes in the original language of the migrants have hardly reached the target groups. The knowledge gap between the native Dutch population and the ethnic minority groups remains unacceptably wide as a result of language barriers with unequal access to knowledge sources, preference to watch the television programmes of the home country, and insufficient availability of health education activities.

We believe intervention should include influencing language barriers, lifestyle, and cultural and religious factors at the same time. Better integration of all ethnic groups in the existing multicultural society of the Netherlands is important, as is a different approach of health care professionals towards these groups.

Mortality in childhood is influenced by many factors, an important one being SES. ${ }^{35}$ We did not match individual data from the child mortality statistics with individual SES data. In the Utrecht study, where not only perinatal but also infant mortality was analysed, inclusion of SES, refined towards neighbourhood level, resulted in a fall in odds ratio for Turkish and Moroccan children by only $10 \%$ percent. $^{13}$ Although SES is an important factor, it is an insufficient explanation for the doubled mortality risk for Turkish and Moroccan children in the Netherlands.

This work originates from a study carried out under a Ministry of Health grant.

1 Geiger A, Korporal J. Health problems and health risks in migrant populations in Germany [in German]. Berlin: WIAD, 1989

2 Peeters RF, van der Veen F. Perinatal and infant mortality of ethnic minorities in Belgium/Flanders [in Flemish]. Publi-

3 Olderburg CEM, Rasmussen F, Cotten NU. Ethnic differences in rates of infant mortality and sudden infant differences in rates of infant mortality and sudden infant
death in Sweden, 1978-1990. European Fournal of Public Health 1997;7:88-94.

4 Roelandt T, Smeets HMAG, Veenman J. Minorities annual 1993 [in Dutch]. Houten: Bohn Stafleu Van Loghum, 1995.

5 Lucassen J, Penninx R. Newcomers, immigrants and their descendants in the Netherlands, 1550-1985 [in Dutch]. Amsterdam: Meulenhoff, 1985 .

6 Mooren GTM, Kleber RJ, van Willigen LHM, Wolters WHG. Refugee children in the Netherlands [in Dutch]. Utrecht: Wilhelmina Children's Hospital, 1993.

7 Doornbos JPR, Nordbeck HJ. Perinatal mortality. Obstetric risk factors in a community of mixed ethnic origin in Amsterdam. Dissertation. Amsterdam: University of Amsterdam, 1985.

8 Hoogenboezem J, Israëls AZ. Mortality and cause of death among Turkish and Moroccan inhabitants in the Nederlands, 1979-1988 [in Dutch]. Monthly Bulletin Health Statistics (CBS) 1990 . 
9 Schulpen TWJ, ed. Mortality differences between migrant and native Dutch children in the Netherlands [in Dutch]. Utrecht: Centre for Migration and Child Health, 1996.

10 van Enk A, Buitendijk S. Perinatal death in migrants (LVR analysis) 1990-1993. In: Schulpen TWJ, ed. Mortality differences between migrant and native Dutch children in the Netherlands. Utrecht: Centre for Migration and Child Health, 1996:9-19.

11 van Enk A, Buitendijk SE, van de Pal K, et al. Perinatal death in ethnic minorities in the Netherlands. $\mathcal{f}$ Epidemiol Community Health 1998;52:735-9

12 van der Wal MF, van Weert-Waltman ML, Reijneveld SA Causes of death of Amsterdam children abroad 19821993; possibilities for prevention [in Dutch]. Ned Tijdsch Geneeskd 1996;140:777-81.

13 van Driel HF, van Steenbergen JE, Gorissen WHM, et al Ethnic and socio-economic differences in perinatal and infant mortality in Utrecht, an analysis [in Dutch]. Tijdschr Sociale Gezondheidsz 1999;77:208-16.

14 Blackmore CA, Savitz DA, Sioban D, et al. Racial difference in the patterns of preterm delivery in central North Caroin the patterns of preterm delivery in central North
lina, USA. Paediatr Perinat Epidemiol 1995;9:281-95.

15 Shiono PH, Klebanoff MA. Ethnic differences in preterm and very preterm delivery. Am $\mathcal{F}$ Public Health 1986;76: and very

16 Parker JD, Schoendorf KC, Keily JL. Associations between measures of socio-economic status and low birthweight, small for gestational age and premature delivery in the United States. Am 7 Epidemiol 1994;4:271-8.

17 Goldenberg RL, Klebanoff MA, Nugent R, et al. Bacterial colonisation of the vagina during pregnancy in four ethnic groups. Am 7 Obstet Gynecol 1996;174:1618-21.

18 Hillier SL, Nugent RP, Eschenbach DA, et al. Association between bacterial vaginosis and preterm delivery of low birth weight infant. N Engl f Med 1995;333:1737-42.

19 Fiscella K. Racial disparities in preterm birth. The role of urogenital infections. Public Health Rep 1996;111:104-13.

20 Moran JS, Aral SO, Jenkins WC, et al. The impact of sexually transmitted diseases on minority populations. Public ally transmitted diseases on

21 Aral SO, Mosher WD, Gates W Jr. Vaginal douching among women of reproductive age in the United States. Am $\mathcal{F} P u b$ lic Health 1992;82:210-14.
22 Llahi-Camp JM, Rai R, Ison C, et al. The association of bacterial vaginosis with a history of second trimester terial vaginosis with a history of secor
miscarriage. Hum Reprod 1996;11:1575-8.

23 de Beer J. How many people from ethnic minorities are there in the Netherlands? [in Dutch]. Maandstatistiek 1995;95/7:9-12.

24 Central Bureau of Statistics (CBS). Annual reports on cause of death, age and gender [in Dutch]. Voorburg: CBS

25 Swinkels H. Smoking and drinking behaviour of Turkish nhabitants of the Netherlands. 1989-1990 [in Dutch]. Monthly Bulletin Health Statistics (CBS) 1992.

26 Bleeker JK, Reelick NF. The health status of Moroccans in the major cities of the Netherlands [in Dutch]. Rotterdam: Municipal Health Service, 1998.

27 Balarajan R, Soni Raleigh V, Botting B. Mortality from congenital malformations in England and Wales: variations by mother's country of birth. Arch Dis Child 1989;64:145763.

28 Bundey S, Alam H, Kaur A, et al. Why do UK-born Pakistani babies have high perinatal and neonatal mortality rates? Paediatr Perinat Epidemiol 1991;5:101-14.

29 Tunçbilec E, Koc I. Consanguineous marriage in Turkey and its impact on fertility and mortality. Ann Hum Genet and its impact

30 Bittles AH. Consanguinity a major variable in studies on North African reproductive behavior, morbidity and mortality. Proceedings of Demographic Heath Surveys, World Conference, 1991

31 Özalp I, CoskunT, Tokol S, et al. Inherited metabolic disorders in Turkey. F Inherit Metab Dis 1990;13:732-8.

32 Junger M, Steehouwe LC. Traffic accidents in children of ethnic minorities [in Dutch]. The Hague: WODC, 1990.

33 van der Wal MF, Pauw-Plomp H. Ethnicity and swimming skills of secondary school children [in Dutch]. Amsterdam: Municipal Health Service, 1996.

34 Schilder CM. Qulitative analysis of mortality differences [in Dutch]. In: Schulpen TWJ, ed. Mortality differences between migrant and native Dutch children in the Netherlands. Utrecht: Centre for Migration and Child Health, 1996:6994.

35 Singh GK, Yu S. US childhood mortality, 1950 through 1993: trend and socio-economic differentials. Am f Public Health 1996;86:505-12. 